\title{
Calculation of solar-energy inputs into melt ponds
}

\author{
Igor A. Podgorny \\ Foint Institute for the Study of the Atmosphere and Ocean, University of Washington, Box 354235, Seallle, WA 98195, U.S.A.
}

\begin{abstract}
The emphasis of this paper is on the partitioning of solar energy in an open plane-parallel melt pond with a Lambertian bottom. Spectral radiative-energy fluxes into the meltwater and underlying ice-ocean layers are calculated analytically as a function of pond-bottom spectral albedo, pond depth and illumination condition. Albedo of the pond bottom is reconstructed from data on pond albedo and depth. Results of calculations are presented for melt ponds of comparatively high and comparatively low reflectivity for a broad range of pond depths and for various illumination conditions. In the 350$700 \mathrm{~nm}$ spectral band, spectrally averaged pond albedo and solar-energy inputs are a function of pond-bottom albedo, pond depth and illumination condition. In the 700-2400 nm spectral band, the partitioning of solar energy in melt ponds depends on pond depth and illumination condition only. The effect of uncertainty in specifying pond-bottom albedo on total energy input into the water layer is relatively small compared to that on spectrally averaged pond albedo and total energy input into the ice-ocean layer.
\end{abstract}

\section{INTRODUCTION}

Recent numerical experiments with sea-ice models (e.g. Ebert and Curry, 1993) have demonstrated the sensitivity of the ice thickness to melt-pond parameterization, including sensitivity to treatment of optical properties of melt ponds. In turn, those depend on (1) physical and structural properties of underlying ice and (2) pond depth. The potential importance of this feedback relation has focused research on development of methods of calculation and parameterization of melt-pond albedo and solar-energy inputs into melt ponds and underlying ice (Ebert and Curry, 1993; Jin and others, 1994; Ebert and others, 1995; Morassutti and LeDrew, 1995; Makshtas and Podgorny, 1996).

There are two main problems associated with studies of the radiative transfer in melt ponds. First, available data on melt-pond albedo in the visible are subject to considerable variability (e.g. Morassutti and LeDrew, 1995), which suggests that the optical properties of the underlying ice are also subject to variability (Makshtas and Podgorny, 1996). On the other hand, in situ radiation measurements within the underlying ice, and ice sampling from beneath the ponds are difficult to make without disturbing the physical and optical properties of the ponded ice. As a consequence of the latter, specification of such inherent optical properties as scattering coefficients and phase functions of ponded ice in the radiative-transfer models still remains a problem.

The purpose of this paper is to present a method of calculating solar-energy fluxes into melt ponds consistent with a general practice of radiation measurements on the ponded ice. Such observations are usually limited to measurements of pond spectral albedo, and depth and registration of illumination conditions. Although measurements of horizontal variations in depth within an individual pond have been made (personal communications from H. Eicken, 1994; A. Makshtas, 1995), any attempts to assess the effects of horizontal variations in pond depth and optical properties of the pond-bottom ice on melt-pond albedo are not known.
Accordingly, a one-dimensional radiative-transfer model is employed, in which spectral radiative-energy fluxes into the water and ice ocean layers are treated as a function of spectral albedo of the pond bottom, pond depth and illumination condition. In turn, pond-bottom albedo is reconstructed from available data on pond albedo and depth. Based on this model, solar-energy inputs into melt ponds of comparatively high and comparatively low reflectivity for a broad range of pond depths, and for various illumination conditions were calculated. Consideration is limited to the case of open melt ponds.

\section{THEORY}

For the sake of simplicity, and due to the paucity of relevant observational data, two main assumptions about melt ponds have been made. These are Lambertian-bottom reflection and plane-parallel geometry. In this case, the only parameter needed to specify optical properties of the underlying ice for a particular wavelength is its spectral albedo, $\alpha_{\mathrm{i}}$. Pond-bottom albedo, therefore, represents bulk scattering effects of the underlying ice. The advantage of this definition is that an $\alpha_{\mathrm{i}}$ value reconstructed from measurements of albedo and depth of a particular pond for a given illumination condition can be then used for calculating albedo and radiative fluxes for the same pond subjected to another type of illumination and having an another depth. It is also assumed that optical properties of the water are known, and scattering in the water based on a theoretical study of Makshtas and Podgorny (1996) is ignored. Using a Monte Carlo model, Makshtas and Podgorny (1996) found that Lambertian scattering at the pond bottom overwhelms small amounts of scattering in the water. Accordingly, optical thickness of the water layer is defined as $\tau_{\mathrm{w}}=\kappa_{\mathrm{w}}\left|h_{\mathrm{w}}\right|$, where $\kappa_{\mathrm{w}}$ is the beam-absorption coefficient of the water and $h_{\mathrm{w}}$ is the thickness of the meltwater layer (or melt-pond depth). The downwelling irradiance at the top of the water 
layer is assigned to be $F_{0}$ for both direct and diffuse modes of illumination.

According to Makshtas and Podgorny (1996), the spectral albedo for a melt pond of optical thickness $\tau_{\mathrm{w}}$ under direct illumination, $\alpha_{\mathrm{w}}$, is given by

$$
\begin{aligned}
& \alpha_{\mathrm{w}}=R\left(\mu_{0}\right)+ \\
& \frac{2 \alpha_{\mathrm{i}}\left(1-R\left(\mu_{0}\right)\right) \int_{0}^{1}(1-R(\eta)) \exp \left(-\frac{\tau_{\mathrm{w}}}{\eta}\right) \mathrm{d} \eta \exp \left(-\frac{\tau_{\mathrm{w}}}{\eta_{0}}\right)}{1-2 \alpha_{\mathrm{i}} \int_{0}^{1}(1-R(\eta)) \exp \left(-\frac{2 \tau_{\mathrm{w}}}{\eta}\right) \mathrm{d} \eta}
\end{aligned}
$$

where $\mu_{0}$ is the cosine of the solar-zenith angle $\theta_{0}, \eta$ is the cosine of the zenith angle in the water layer, $R\left(\mu_{0}\right)$ and $R(\eta)$ are Fresnel reflections coefficients for irradiance incident on the air-water from above and from below, respectively, $\mu_{0}$ and $\eta_{0}$ are related by $\sqrt{1-\mu_{0}^{2}}=n_{\mathrm{w}} \sqrt{1-\eta_{0}^{2}}$ (Snell's law), and $n_{\mathrm{w}}$ is the refractive index of the water.

We now designate $H_{\mathrm{w}}$ and $H_{\mathrm{i}}+H_{\mathrm{oc}}$ as the net spectral radiative-energy fluxes absorbed by the pond water and ice (including the ocean under the ponded ice). $H_{\mathrm{i}}+H_{\mathrm{oc}}$ is obtained from

$$
H_{\mathrm{i}}+H_{\mathrm{oc}}=\frac{\left(1-R\left(\mu_{0}\right)\right)\left(1-\alpha_{\mathrm{i}}\right) F_{0} \exp \left(-\frac{\tau_{\mathrm{w}}}{\eta_{\mathrm{o}}}\right)}{1-2 \alpha_{\mathrm{i}} \int_{0}^{1}(1-R(\eta)) \exp \left(-\frac{2 \tau_{\mathrm{w}}}{\eta}\right) \mathrm{d} \eta}
$$

and $H_{\mathrm{w}}$ from

$$
H_{\mathrm{w}}=\left(1-\alpha_{\mathrm{w}}\right) F_{0}-\left(H_{\mathrm{i}}+H_{\mathrm{oc}}\right) .
$$

Spectral albedo and radiative-energy fluxes under cloudy conditions are calculated assuming that the diffuse downwelling radiance at the top of the water is isotropic. The spectral albedo for a melt pond of optical thickness $\tau_{\mathrm{w}}$ illuminated by uniform diffuse radiance, $\hat{\alpha}_{w}$, is given by

$$
\begin{aligned}
\hat{\alpha}_{\mathrm{w}}=2 \int_{0}^{1} R(\mu) \mu \mathrm{d} \mu \\
+\frac{4 \alpha_{\mathrm{i}} n_{\mathrm{w}}{ }^{2}\left(\int_{0}^{1}(1-R(\eta)) \exp \left(-\frac{\tau_{\mathrm{w}}}{\eta}\right) \mathrm{d} \eta\right)^{2}}{1-2 \alpha_{\mathrm{i}} \int_{0}^{1}(1-R(\eta)) \exp \left(-\frac{2 \tau_{\mathrm{w}}}{\eta}\right) \mathrm{d} \eta} .
\end{aligned}
$$

Similarly,

$$
\hat{H}_{\mathrm{i}}+\hat{H}_{\mathrm{oc}}=\frac{2 n_{\mathrm{w}}{ }^{2}\left(1-\alpha_{\mathrm{i}}\right) F_{0} \int_{0}^{1}(1-R(\eta)) \exp \left(-\frac{\tau_{\mathrm{w}}}{\eta}\right) \mathrm{d} \eta}{1-2 \alpha_{\mathrm{i}} \int_{0}^{1}(1-R(\eta)) \exp \left(-\frac{2 \tau_{\mathrm{w}}}{\eta}\right) \mathrm{d} \eta},
$$

$$
\hat{H}_{\mathrm{w}}=\left(1-\hat{\alpha}_{\mathrm{w}}\right) F_{0}-\left(\hat{H}_{\mathrm{i}}+\hat{H}_{\mathrm{oc}}\right) .
$$

More details about development of the forward model can be found in Makshtas and Podgorny (1996) and Podgorny and Grenfell (1996). Furthermore, as relationships between $\alpha_{\mathrm{w}}$ and $\alpha_{\mathrm{i}}$, and between $\hat{\alpha}_{\mathrm{w}}$ and $\alpha_{\mathrm{i}}$ are established in an analytical form, $\alpha_{\mathrm{i}}$ can be easily derived from melt-pond albedo and depth assuming that $\kappa_{\mathrm{w}}$ and illumination condition are given (Podgorny and Grenfell, 1996).

Dimensionless quantities $\Psi_{\mathrm{a}}^{\mathrm{m}}$, and dimensionless radiative-energy fluxes into the water $\Psi_{\mathrm{w}}^{\mathrm{m}}$ and ice-ocean layers
$\Psi_{\mathrm{i}}^{\mathrm{m}}+\Psi_{\mathrm{oc}}^{\mathrm{m}}$ are introduced for the mth spectral band as follows

$$
\Psi_{\mathrm{a}}^{\mathrm{m}}=\frac{\int_{\Delta_{\mathrm{m}}} \alpha_{\mathrm{w}}(\lambda) F_{0}(\lambda) \mathrm{d} \lambda}{\sum_{\mathrm{m}} \Delta_{\mathrm{m}} F_{0}(\lambda) \mathrm{d} \lambda}, \Psi_{\mathrm{j}}^{\mathrm{m}}=\frac{\int_{\Delta_{\mathrm{m}}} H_{\mathrm{j}}(\lambda) \mathrm{d} \lambda}{\int_{\mathrm{m}} \Delta_{\mathrm{m}} F_{0}(\lambda) \mathrm{d} \lambda} .
$$

Here index j denotes subscripts "w", "i" or "oc", $F_{0}(\lambda)$ is the distribution of the incident-spectral irradiance and $\lambda$ is the wavelength. Clearly,

$$
\sum_{m, j} \Psi_{j}^{m}=1 .
$$

The $\Psi_{\mathrm{a}}^{\mathrm{m}}, \Psi_{\mathrm{w}}^{\mathrm{m}}$ and $\Psi_{\mathrm{i}}^{\mathrm{m}}+\Psi_{\mathrm{oc}}^{\mathrm{m}}$ values specify redistribution of the incident solar energy among the energy returning to the atmosphere and stored in the water and ice ocean layers in the $\Delta_{\mathrm{m}}$ band. Spectrally averaged albedo of the melt pond is $\sum_{\mathrm{m}} \Psi_{\mathrm{a}}^{\mathrm{m}}$.

\section{DATA}

In this paper, wavelengths ranging from 350 to $2400 \mathrm{~nm}$ are focused upon. The $\kappa_{\mathrm{w}}$ values in the $350-800$ and $800-1140$ $\mathrm{nm}$ wavelength regions are taken from Smith and Baker (1981) and Kou and others (1993), respectively. At the wavelengths exceeding $1140 \mathrm{~nm}$ all incident radiation penetrating into the water layer through the air-water interface is assumed to be completely absorbed by the water. The $n_{\mathrm{w}}$ values in the $350-700 \mathrm{~nm}$ wavelength region are calculated using an empirical equation derived by Quan and Fry (1995). Calculations of $n_{\mathrm{w}}$ are made for the temperature $0^{\circ} \mathrm{C}$ and the salinity $3 \%$. For the wavelengths larger than $700 \mathrm{~nm}$, the $n_{\mathrm{w}}$ values are adapted from Hale and Query (1973).

In order to specify $\alpha_{\mathrm{i}}$, pond albedo and depth data relevant to ponds of comparatively high and comparatively low reflectivity in the visible are used. The idea is to characterize the early and late stages of the underlying ice during the summer melt period. Accordingly, the ponds used are referred to as the young and old melt ponds. Albedo measurements for the young pond were made in the beginning of July 1974 near ice island T-3 under an almost clear sky. The solar-zenith angle was about $65^{\circ}$ and the pond depth was $0.25 \mathrm{~m}$. Albedo measurements for the old melt pond were made in the beginning of August 1974 on ice island T-3. The solar-zenith angle was about $71^{\circ}$ and the pond depth was $0.3 \mathrm{~m}$. More details about measurement procedure can be found in Grenfell and Maykut (1977). Figure l shows meltpond spectral albedos in the visible used as input data for the calculations. The infrared albedos are not shown since they reduce to the Fresnel reflection limit (e.g. Grenfell and Perovich, 1984).

The incident spectral irradiances used for clear and cloudy skies are shown in Figure 2. The values given are adapted from Grenfell and Perovich (1984) and Grenfell (1991). For the clear-sky case, all the radiation reaching the surface is assumed to be direct, neglecting scattering in the atmosphere. For the cloudy-sky case, the radiation reaching the surface is assumed to be isotropic.

\section{GALGULATIONS AND DISGUSSION}

The algorithm for calculating solar-energy inputs into melt ponds is as follows. Initially, $\alpha_{\mathrm{i}}$ is reconstructed from the 


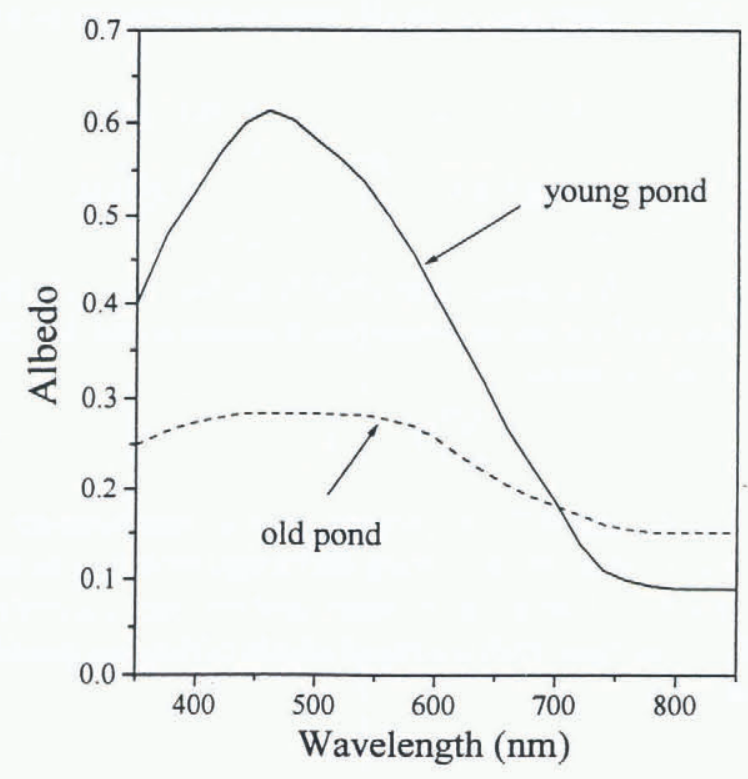

Fig. 1. Spectral albedo for the young and old melt ponds.

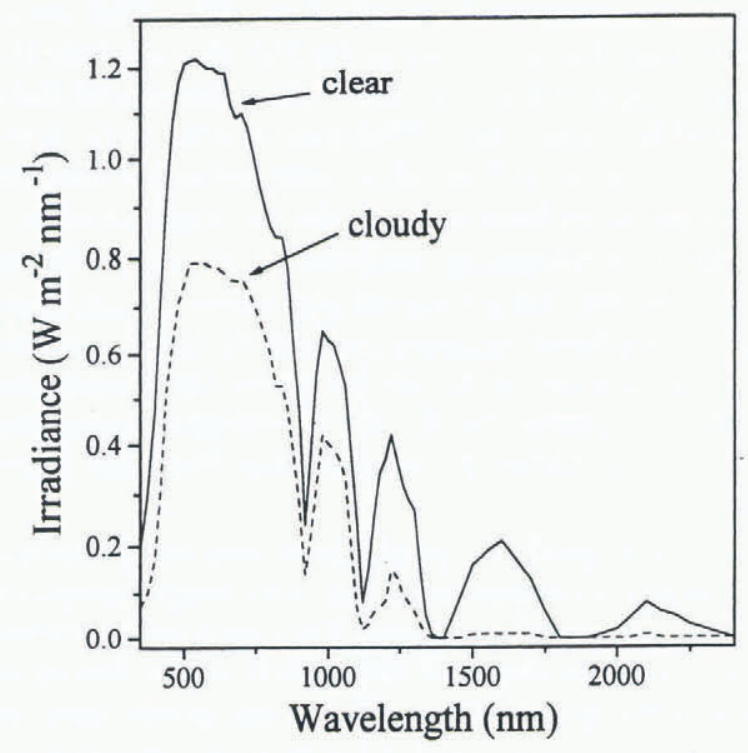

Fig. 2. The incident spectral irradiances under clear and cloudy skies.

data on $\alpha_{\mathrm{w}}, H_{\mathrm{w}}$ and $\theta_{0}$ for the young and old ponds. Then $H_{\mathrm{w}}, H_{\mathrm{i}}+H_{\mathrm{oc}}, \hat{H}_{\mathrm{w}}$ and $\hat{H}_{\mathrm{i}}+\hat{H}_{\mathrm{oc}}$ are computed for various pond depths and illumination conditions based on Equations (2), (3), (5) and 6). The relevant values of melt-pond spectral albedo are computed based on Equations (1) and (4).

Figure 3 shows the spectral radiative-energy fluxes into the water (solid line) and ice--ocean (dashed line) layers vs wavelength for the ponds of high (top) and low (bottom) reflectivity under clear skies. Because the same values of pond depth $(0.3 \mathrm{~m})$ and solar-zenith angle $\left(60^{\circ}\right)$ have been applied to both ponds in this case, the only reason for differences between the curves corresponding to the young and old ponds is different albedos of the pond bottom. As seen from Figure 3, the effect of bottom albedo on $H_{\mathrm{i}}+H_{\mathrm{oc}}$ is significant over the entire visible spectrum. The effect of bottom albedo on $H_{\mathrm{w}}$ is not so pronounced, and can be observed only at the wavelengths ranging from 600 to $700 \mathrm{~nm}$. With respect to calculating the $\Psi_{\mathrm{j}}^{\mathrm{m}}$ values, it is convenient, therefore, to divide wavelength region under consideration into two spectral bands: $\Delta_{1}=350-700 \mathrm{~nm}$ and $\Delta_{1}=700-2400 \mathrm{~nm}$.
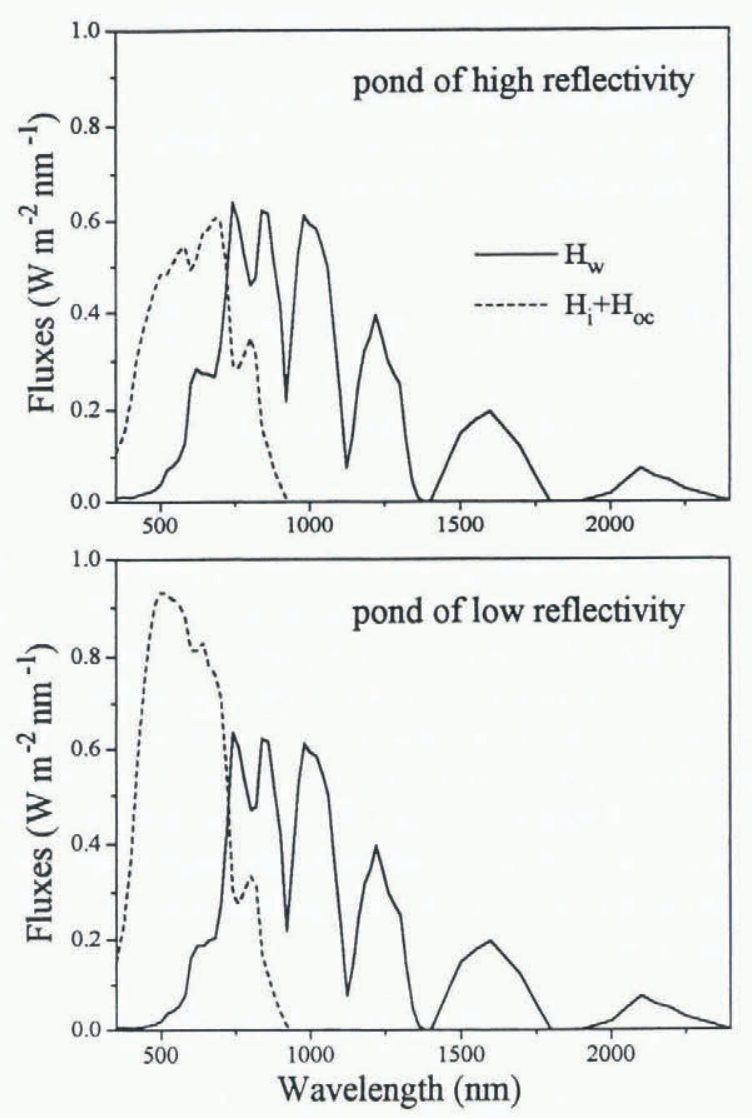

Fig. 3. The spectral radiative-energy fluxes into the water and ice ocean layers under clear skies (pond depth $-0.3 \mathrm{~m}$, the solar-zenith angle $-60^{\circ}$ ).

Table 1 presents the $\Psi_{\mathrm{j}}^{\mathrm{m}}$ values for both ponds under clear and cloudy skies vs pond depth. Table 2 presents the $\Psi_{\mathrm{j}}^{\mathrm{m}}$ values under clear skies vs the solar-zenith angle. Again, redistribution of solar energy is a strong function of bottom albedo in the 350 to $700 \mathrm{~nm}$ spectral band, but it is nearly the same for both ponds in the $700-2400 \mathrm{~nm}$ spectral band. In order to investigate sensitivity of the calculated $\Psi_{\mathrm{j}}^{\mathrm{m}}$ values to specification of pond-bottom albedo, we introduce a quantity

$$
\delta_{\mathrm{j}}=\mid \sum_{\mathrm{m}}\left(\Psi(\text { young })_{\mathrm{j}}^{\mathrm{m}}-\Psi(\text { old })_{\mathrm{j}}^{\mathrm{m}}\right) \mid,
$$

where index $\mathrm{j}$ is used in the same sense as in Equation (7). Because optical properties of pond-bottom ice seem to fall between those of the young and old ponds in most cases, the $\delta_{\mathrm{j}}$ values provide a convenient measure of the maximum error in calculating the solar energy reflected by pond and deposited in the water and ice-ocean layers due to uncertainty in specifying the albedo of the pond bottom. Based on the results presented in Table 1 , for example, we find that $\delta_{\mathrm{a}}, \delta_{\mathrm{w}}$ and $\delta_{\mathrm{i}}+\delta_{\mathrm{oc}}$ are in the range $9-14 \%, 0-3 \%$ and $12-$ $13 \%$ of total incident radiation in the $350-2400 \mathrm{~nm}$ wavelength region, respectively. Assuming that depth of the melt ponds does not exceed $1 \mathrm{~m}, \delta_{\mathrm{w}}$ is always less by an order of magnitude than $\sum_{\mathrm{m}} \Psi_{\mathrm{w}}^{\mathrm{m}}$. In turn, $\delta_{\mathrm{a}}$ and $\delta_{\mathrm{i}}+\delta_{\mathrm{oc}}$ can be nearly as large as $\sum_{\mathrm{m}} \Psi_{\mathrm{a}}^{\mathrm{m}}$ and $\sum_{\mathrm{m}}\left(\Psi_{\mathrm{i}}^{\mathrm{m}}+\Psi_{\mathrm{oc}}^{\mathrm{m}}\right)$ which suggests a greater sensitivity of these quantities to optical properties of the pond-bottom ice.

Although our algorithm includes effects of multiple reflections in melt ponds, it is relatively simple with respect to numerical realization. Fresnel reflection integrals in Equations (1), (2), (4) and (5) can easily be computed ex- 
Table 1. Partitioning of solar energy (\% of total incident radiation in the 350-2400 $\mathrm{nm}$ wavelength region) in the ponds of high and low (in parentheses) reflectivity as a function of pond depth

Pond depth

m

\begin{tabular}{|c|c|c|c|c|c|c|}
\hline & $\Psi_{\mathrm{a}}^{1}$ & $\Psi_{w}{ }^{1}$ & $\Psi_{1}^{1}+\Psi_{\mathrm{oc}}{ }^{1}$ & $\Psi_{\mathrm{a}}^{2}$ & $\Psi_{\mathrm{w}}{ }^{2}$ & $\Psi_{1}^{2}+\Psi_{o c}^{2}$ \\
\hline \multicolumn{7}{|c|}{ Clear skies, $\theta_{0}=60^{\circ}$} \\
\hline 0.1 & $21.8(8.9)$ & $2.2(1.4)$ & $22.3(36.0)$ & $3.9(3.7)$ & $34.7(34.7)$ & $15.1(15.3)$ \\
\hline 0.3 & $20.3(8.5)$ & $5.5(3.7)$ & $20.5(34.1)$ & $3.5(3.4)$ & $42.8(42.7)$ & $7.4(7.6)$ \\
\hline 1.0 & $16.9(7.5)$ & $12.8(9.5)$ & $16.5(29.3)$ & $3.2(3.2)$ & $49.2(49.0)$ & $1.4(1.5)$ \\
\hline 0.03 & $25.1(10.4)$ & $0.8(0.5)$ & $26.1(41.1)$ & $4.5(4.2)$ & $15.5(15.5)$ & $28.0(28.3)$ \\
\hline 0.1 & $24.3(10.2)$ & $2.5(1.5)$ & $25.2(40.3)$ & $4.1(3.9)$ & $24.8(24.8)$ & $19.1(19.3)$ \\
\hline 0.3 & $22.6(9.8)$ & $6.3(4.1)$ & $23.1(38.1)$ & $3.6(3.5)$ & $34.4(34.3)$ & $10.0(10.2)$ \\
\hline 1.0 & $18.8(8.6)$ & $14.6(10.7)$ & $18.5(32.7)$ & $3.3(3.2)$ & $42.7(42.5)$ & $2.1(2.3)$ \\
\hline
\end{tabular}

Table 2. As in Table 1, but for clear skies only as a function of solar-zenith angle $\theta_{0}$
Band II

$700-2400 \mathrm{~nm}$

\author{
$550-700 \mathrm{~nm}$
}

$$
\begin{aligned}
& 22.3(36.0) \\
& 20.5(34.1) \\
& 16.5(29.3)
\end{aligned}
$$

$42.8(42.7$

$7.4(7.6)$

$1.4(1.5$

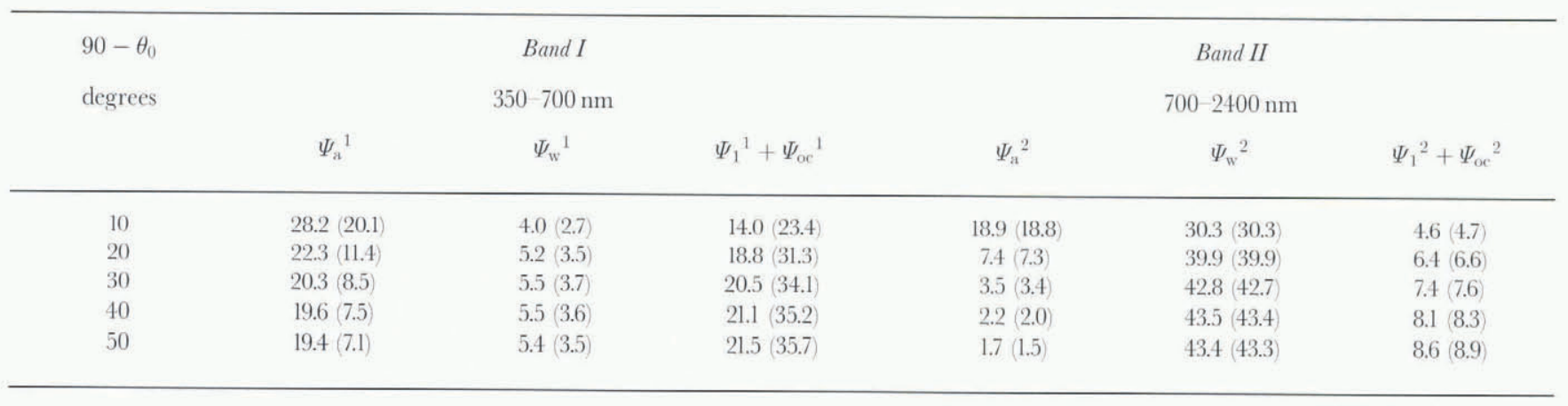

panding $\exp \left(-\tau_{\mathrm{w}} / \eta\right)$ and $\exp \left(-2 \tau_{\mathrm{w}} / \eta\right)$ in power series (Makshtas and Podgorny, 1996). Therefore, one of the possible applications of the developed algorithm is parameterization of pond albedo and solar-energy inputs into melt ponds for the use in sea-ice models. Because effects of pond depth and illumination condition on redistribution of solar energy in a plane-parallel melt pond can easily be incorporated into such a parameterization, additional efforts are needed only to parameterize pond-bottom albedo. In view of the variability of the optical properties of ponded ice, this parameterization should rely on a large quantity of measurements of pond albedo and depth for each particular type of the ponded ice (e.g. first-year, multiyear, white, blue, contaminated, etc.) in order to be statistically significant. Although the method presented here takes into account dependence of pond albedo and solar-energy inputs on illumination condition and hence on latitude, different parameterization of pond-bottom albedo can probably be required for the Eurasian and Canadian sectors of the Arctic, reflecting effect of contaminants on the melt ponds in the central Arctic and on Siberian shelves (Eicken and others, 1994).

As already mentioned, the above calculations have been made under two simplifying assumptions about melt ponds: Lambertian bottom reflection and plane-parallel geometry. Although the first is not generally true, it seems to be too early to proceed to a more sophisticated assumption about pond-bottom reflection because no observations of angular distribution of reflected radiation within melt ponds are available at present. Such measurements could be used for the development of a more detailed forward model of the radiative transfer in a melt pond with a non-Lambertian bottom and a more accurate parameterization of pondbottom albedo.

Finally, a question of particular concern to the problem under consideration is incorporation of horizontal heterogeneity of pond-bottom albedo and variations in pond depth into melt-pond parameterization. A compromise approach to evaluating solar-energy disposition in sea ice with a complex geometry is that in which the radiative transfer in sea ice is assumed to be dependent on local optical properties of the ice, but independent of these values in neighboring regions (e.g. Perovich, 1990). Any net horizontal photon transport is neglected under such an assumption. Although quantitative estimates of the relevant errors have never been made, one can assume that this approach will result in larger errors when applied to a melt pond on the multiyear ice, reflecting a complex surface relief of the multiyear ice. As a consequence of general limitations imposed by one-dimensional models, numerical experiments with three-dimensional radiative-transfer models are required before the above question can be answered.

\section{CONGLUSIONS}

Partitioning of solar energy in an open plane-parallel melt pond with a Lambertian bottom has been investigated. In the $350-700 \mathrm{~nm}$ wavelength band, spectrally averaged pond albedo and solar-energy inputs into melt ponds are a func- 
tion of pond-bottom albedo, pond depth and illumination condition. In the 700-2400 nm wavelength band, the partitioning of solar energy in melt ponds depends only on pond depth and illumination condition. Finally, beyond approximately $1000 \mathrm{~nm}$ it should only depend on illumination condition, because the incident irradiance reaching the ice layer is negligible for actual melt-pond depths. The effect of uncertainty in specifying pond-bottom albedo on total energy input into the water layer is relatively small compared to that on spectrally averaged pond albedo and total energy input into the ice- ocean layer.

A possible output from the algorithm could be parameterization of pond albedo and solar-energy inputs into the water and ice-ocean layers for the use in sea-ice models. The first step in this direction should be development of a statistically significant parameterization of pond-bottom albedo for various types of the underlying ice. This can be made either based on available data on melt-pond albedo and depth or by using direct measurements of pond-bottom albedo within the meltwater layer.

\section{ACKNOWLEDGEMENTS}

The author is grateful to T. Grenfell, J. Key, G. Maykut and D. Perovich for helpful discussions, comments on the manuscript and providing data on melt-pond albedo and incident irradiance. This research was supported by the Joint Institute for the Study of the Atmosphere and Ocean contribution 369.

\section{REFERENGES}

Ebert, E. E. and J. A. Curry. 1993. An intermediate one-dimensional thermodynamic sea ice model for investigating ice-atmosphere interactions. J. Geophys. Res., 98 (C6), 10,085-10,109.

Ebert, E. E., J. L. Schramm and J. A. Curry. 1995. Disposition of solar radiation in sea ice and the upper ocean. 7. Geophys. Res., 100 (C8), 15,965$15,996$.

Eicken, H. and 10 others. 1994. Distribution, structure and hydrography of surface melt puddles. Ber. Polarforsch. 149, 73-76.

Grenfell, T. C. 1991. A radiative transfer model for sea ice with vertical structure variations. J. Geophys. Res., 96 (C9), 16,991-17,001.

Grenfell, T. C. and G. A. Maykut. 1977. The optical properties of ice and snow in the Arctic Basin. J. Glaciol., 18(80), 445-463.

Grenfell, T. C. and D. K. Perovich. 1984. Spectral albedos of sea ice and incident solar irradiance in the southern Beaufort Sea. J. Geophys. Res. 89 C3), 3573-3580.

Hale, G. M. and M. R. Query. 1973. Optical constants of water in the 200$\mathrm{nm}$ to $200-\mu \mathrm{m}$ wavelength region. Appl. Opt., $12(3), 555-563$.

Jin, Z., K. Stamnes, W. F. Weeks and S.-C. Tsay. 1994. The effect of sea ice on the solar energy budget in the atmosphere sea ice-ocean system: a model study. J. Geophys. Res., 99 (C12), 25,281-25,294.

Kou, L. H., D. Labrie and P. Chylek. 1993. Refractive indices of water and ice in the 0.65 to $2.5 \mu \mathrm{m}$ spectral range. Appl. Opt., 32 (19), 3531-3540.

Makshtas, A. P. and I. A. Podgorny. 1996. Calculation of melt pond albedos on Arctic sea ice. Polar Res., 15(1), 43-52.

Morassutti, M. P. and E. F. LeDrew. 1995. Melt pond dataset for use in sea-ice and climate-related studies. Waterloo, Ont., University of Waterloo. Institute for Space and Terrestrial Science. Earth-Observations Laboratory. (Tech. Rep. Ser. ISTS-EOL-TR95-001.

Perovich, D. K. 1990. Theoretical estimates of light reflection and transmission by spatially complex and temporally varying sea ice covers. 7 . Geophys. Res., 95 (C6), 9557-9567.

Podgorny, I. A. and T. C. Grenfell. 1996. Partitioning of solar energy in melt ponds from measurements of pond albedo and depth. 7. Geophys. Res., $101(\mathrm{ClO}), 22,737-22,748$.

Quan, X. and E. S. Fry. 1995. Empirical equation for the index of refraction of seawater. Appl. Opt., 34(18), 3477-3480.

Smith, R. C. and K. S. Baker, 1981. Optical properties of the clearest natural waters $(200-800 \mathrm{~nm})$. Appl. Opt., 20(2), 177-184. 